\title{
Orthographic influences in spoken word recognition: The consistency effect in semantic and gender categorization tasks
}

\author{
Ronald Peereman \\ Université de Bourgogne, Dijon, France \\ and Université Pierre Mendes-France, Grenoble, France \\ SOPHIE DUFOUR \\ Université Aix-Marseille, Marseille, France \\ AND \\ JENNIFER S. BURT \\ University of Queensland, Brisbane, Queensland, Australia
}

\begin{abstract}
According to current models, spoken word recognition is driven by the phonological properties of the speech signal. However, several studies have suggested that orthographic information also influences recognition in adult listeners. In particular, it has been repeatedly shown that, in the lexical decision task, words that include rimes with inconsistent spellings (e.g., /-ip/ spelled -eap or -eep) are disadvantaged, as compared with words with consistent rime spelling. In the present study, we explored whether the orthographic consistency effect extends to tasks requiring people to process words beyond simple lexical access. Two different tasks were used: semantic and gender categorization. Both tasks produced reliable consistency effects. The data are discussed as suggesting that orthographic codes are activated during word recognition, or that the organization of phonological representations of words is affected by orthography during literacy acquisition.
\end{abstract}

Language abilities are a human evolutionary endowment. Every social group uses spoken language, and all children appropriately exposed to the mother tongue learn spoken language without explicit instruction. By contrast, writing systems correspond to recent cultural inventions for representing phonological and morphological information, whose earliest signs go back to around 5,000 years. Not all spoken languages have a corresponding written form, and when they have, learning to read and write requires specific instruction. The primacy of spoken over written languages has therefore led researchers to assume that the acquisition of reading/spelling abilities capitalizes on the cognitive structures that are specialized for spoken language (e.g., Liberman, 1992), and numerous observations have converged in showing that children are highly dependent on phonology during literacy acquisition. In the present study, we examine the hypothesis that the most recently acquired ability, literacy, introduces changes, in turn, in how spoken words are recognized.

Spoken word recognition requires listeners to match the speech signal to phonological representations of words stored in memory. Although, at first sight, orthography does not logically intervene during the word recognition processes, several behavioral or neuroimaging data have suggested that orthography affects auditory tasks. For example, determining whether two spoken words share the same rhyme is facilitated when the rhymes are spelled identically (as in pie-tie, but not in rye-tie; Seidenberg \& Tanenhaus, 1979), and activation of brain regions involved in the mapping between orthography and phonology has been shown during rhyme detection (Booth et al., 2004). Orthographic influences have also been reported for tasks requiring participants to determine whether a particular target phoneme occurs in spoken words (e.g., Dijkstra, Roelofs, \& Fieuws, 1995; Hallé, Chéreau, \& Segui, 2000), performance being affected by the spelling of the target phoneme in the carrier word (e.g., $K$ or $C$ for the $/ \mathrm{k} /$ phoneme; $P$ or $B$ for the $/ \mathrm{p} /$ phoneme).

Whereas spoken word recognition is fast and effortless in both literate and illiterate peoples, performance on metalinguistic tasks, such as phoneme detection, is well known to depend on literacy acquisition in alphabetical writing systems (Cheung, Chen, Lai, Wong, \& Hills, 2001; Morais, Cary, Alegria, \& Bertelson, 1979), and it is therefore unclear whether the processes engaged in such tasks reflect normal word recognition. More direct evidence of orthographic influences during spoken word recognition was achieved by the manipulation of

R. Peereman, ronald.peereman@upmf-grenoble.fr 
orthographic consistency in auditory lexical decision tasks. Orthographic consistency refers to the degree of systematicity of phonology-to-orthography mappings, so that consistency decreases when multiple orthographic renderings are possible for the same sounds (e.g., /ip/ in heap and deep). Generally, the idea motivating such a manipulation is that orthographic codes should be activated from phonology to affect recognition and that erroneous orthographic activation from phonology is more likely to occur when some of the word's sounds can be associated with various orthographies (as in /ip/) than when a unique spelling exists (e.g., obe for $/ \mathrm{Ob} /$, as in probe). Ziegler and Ferrand (1998) reported that words with inconsistently spelled rimes yielded slower lexical decisions than did words with an orthographically consistent rime, an observation that was confirmed by subsequent auditory lexical decision studies (Ventura, Morais, Pattamadilok, \& Kolinsky, 2004; Ziegler, Ferrand, \& Montant, 2004). Furthermore, using the same task, Perre and Ziegler (2008) recently reported event-related brain potential differences between consistent and inconsistent words.

Given the assumption that orthographic knowledge plays a role during auditory processing, one should expect orthographic consistency to have an impact in auditory tasks other than lexical decision. Thus far, no clear picture has emerged, however. Although small consistency effects have occasionally been described in tasks requiring the repetition of auditory words (Peereman, Bonin, \& Dufour, 2008; Ziegler et al., 2004), in other studies, no effect has been reported (Pattamadilok, Morais, Ventura, \& Kolinsky, 2007; Ventura et al., 2004). That there is a lack of converging evidence from different tasks may indicate that the strong consistency effect observed in the lexical decision task follows from particular processes engaged in evaluating the lexical status of the stimuli. For example, in the framework of the lexical decision model proposed by Grainger and Jacobs (1996) for printed words, responses can be based on the overall activation produced within the mental lexicon. Because, in general, orthographically consistent words are orthographically similar to a larger number of words than are inconsistent words, they should produce higher overall activations within the orthographic lexicon, leading to faster word responses.

Clearly, finding similar influences of orthographic consistency in various tasks would reinforce the hypothesis that orthographic knowledge affects the core processes of spoken word recognition. Our first goal, therefore, was to examine the orthographic consistency effect in two different tasks: semantic categorization and grammatical gender categorization. The choice of the tasks was motivated by two different requirements. First, the two tasks differed on the nature of knowledge (i.e., semantic or grammatical gender) contributing to the participant's responses. Hence, an account of orthographic influences in terms of task-specific mechanisms would be less likely if both tasks were affected by consistency. A second requirement was to depart from tasks requiring simple lexical access. Indeed, supposing that orthography is involved in lexical access, its influence in retrieving semantic and gram- matical knowledge might vanish, given that we listen to speech more than we read, and thus semantic/grammatical knowledge might be more strongly connected with phonology than with orthography (see Van Orden, Pennington, \& Stone, 1990, for a similar argument).

Orthographic consistency of French words was manipulated in semantic and gender categorization tasks. In the semantic categorization task, one of two category names was first presented, followed by the target word. Participants had to decide whether the target word was a member or not of the semantic category presented just before. In the gender categorization task, participants had to decide whether the word stimuli were feminine or masculine.

\section{METHOD}

\section{Participants}

Seventy-eight undergraduate students at the University of Bourgogne took part in the experiments. Forty-two of them performed the semantic categorization task, and 36 performed the gender categorization task. All were native French speakers.

\section{Stimuli}

Semantic categorization task. Fifty-four French monosyllabic words served as targets. Half of them were orthographically consistent, and half were inconsistent. Orthography consistency was operationally defined as a function of the rime-body mappings, and consistency estimates were taken from the LEXOP database (Peereman \& Content, 1999). In LEXOP, the phonology-orthography consistency index corresponds to the number of words containing a given rime unit with the same orthography divided by the number of words containing that rime. In the case of total consistency, the index is equal to 1 . The two stimulus sets were matched as far as possible on several critical variables (see Table 1). Each target word could be categorized as referring either to a natural element or phenomenon (e.g., loup [wolf], sable [sand]) or to a result of human activity (e.g., harpe [harp], stade [stadium]). Due to the numerous constraints in stimulus selection, it was not possible to fully match the number of consistent and inconsistent words across the semantic categories. There were 15 consistent and 14 inconsistent words assigned to the first category and 12 consistent and 13 inconsistent words assigned to the second category. For each stimulus, categorization difficulty was estimated by an independent group of 30 students. They had to estimate how much each word was close to one of the two endpoints of a 6-point scale, the first point for words corresponding to natural elements or phenomena and the last point for words corresponding to objects, inventions, or constructs resulting from human activity. The participants' judgments were converted to numerical values ranging from 1 (natural category) to 6 (human category), and mean deviations from the appropriate category label (used in the experiment) were computed separately for consistent and inconsistent words to index categorization difficulty. As Table 1 indicates, the two word sets yielded similar estimates of categorization difficulty. Finally, for the purpose of the semantic categorization task, 54 filler words calling for a no response were added in the stimulus list. Twenty-five fillers corresponded to exemplars of the natural category, and 29 to exemplars of the human category.

Gender categorization task. The stimuli consisted of 28 consistent and 28 inconsistent words. As Table 1 indicates, the two stimulus sets were matched along several critical variables. As for the semantic categorization task, it was not possible to have identical numbers of consistent and inconsistent words across gender categories. Twenty-four words had a feminine gender (13 consistent and 11 inconsistent words), and 32 words had a masculine gender (15 consistent and 17 inconsistent). Because previous studies (e.g., Bordag, Opitz, \& Pechmann, 2006; Holmes \& Dejean de la Bâtie, 
Table 1

Characteristics of the Stimulus Words (Mean Values)

\begin{tabular}{|c|c|c|c|c|c|c|}
\hline \multirow[b]{2}{*}{ Variables } & \multicolumn{3}{|c|}{ Semantic Categorization } & \multicolumn{3}{|c|}{ Gender Categorization } \\
\hline & Consistent & Inconsistent & $t$ Test & Consistent & Inconsistent & $t$ Test \\
\hline Orthographic consistency & .92 & .26 & $* * *$ & .96 & .36 & $* * *$ \\
\hline Word duration (msec) & 638 & 632 & n.s. & 671 & 668 & n.s. \\
\hline Word frequency & 26 & 43 & n.s. & 9 & 7 & n.s. \\
\hline Log word frequency & 1.05 & .97 & n.s. & .82 & .66 & n.s. \\
\hline Number of phonemes & 3.59 & 3.41 & n.s. & 3.93 & 3.68 & n.s. \\
\hline Uniqueness point & 4.44 & 4.04 & $* *$ & 4.57 & 4.25 & n.s. \\
\hline Phonological neighborhood & 18.59 & 18.41 & n.s. & 12.86 & 15.86 & n.s. \\
\hline Initial phoneme frequency & 7,328 & 7,123 & n.s. & 7,933 & 6,745 & n.s. \\
\hline Initial biphone frequency & 653 & 501 & n.s. & 622 & 441 & n.s. \\
\hline Semantic categorization difficulty & .40 & .38 & n.s. & - & - & - \\
\hline \multicolumn{7}{|l|}{ Gender consistency } \\
\hline Initial phonemes $(1,2$, or 3$)$ & - & - & - & $.51, .51, .54$ & $.51, .49, .55$ & n.s. \\
\hline Ending phonemes $(1,2$, or 3$)$ & - & - & - & $.49, .61, .60$ & $.55, .64, .73$ & n.s. \\
\hline Initial letters $(1,2$, or 3$)$ & - & - & - & $.51, .52, .54$ & $.52, .53, .65$ & n.s., n.s., * \\
\hline Ending letters $(1,2$, or 3$)$ & - & - & - & $.49, .52, .57$ & $.67, .68, .78$ & $* *, *, * *$ \\
\hline
\end{tabular}

Note-Orthographic consistency values are from LEXOP (Peereman \& Content, 1999); word frequency (per million) is from Lexique 3 (New, Pallier, Brysbaert, \& Ferrand, 2004). Uniqueness point and phonological neighborhood (by type counts) are from Vocolex (Dufour, Peereman, Pallier, \& Radeau, 2002). Initial-phoneme frequency, initial-biphone frequency, and gender consistency were computed from Lexique 2. Gender consistency was estimated using phonemes or letter strings of various lengths (from one to three phonemes or letters), and starting from the word initial or word final position. Semantic categorization difficulty was estimated by an independent group of participants (see the text for details). $\quad{ }^{*} p<.05 . \quad{ }^{* *} p<.01 .{ }^{* * *} p<.001$.

1999) had shown that phonological/orthographic sublexical cues can help gender categorization (e.g., words ending with the letter $e$ are often feminine), gender consistency of the stimulus was estimated. Gender consistency indices were obtained for each word by computing the number of words that had a given phonological (or orthographic) string in common with the stimuli and had the same gender, divided by the total number of words that contained that particular string. Gender consistency values were obtained for word-initial and word-final strings made up of one to three phonemes or letters, using the Lexique database (New, Pallier, Brysbaert, \& Ferrand, 2004). Although the two stimulus sets were well matched for gender consistency computed on phonological strings (from one to three phonemes long, starting from the initial or the final phonemes), they differed in gender consistency computed on orthographic strings. However, this difference should work against the orthographic consistency effect because, on average, the orthographically inconsistent items were more gender consistent than the orthographically consistent ones.

\section{Procedure}

The stimuli were recorded by a female native speaker of French, at a sampling rate of $44 \mathrm{kHz}$. The participants were tested individually in a quiet room. The experiment was run on a Macintosh computer controlled by PsyScope software (Cohen, MacWhinney, Flatt, \& Provost, 1993). The stimuli were presented randomly through headphones at a comfortable sound level. Each trial of the semantic categorization task began with the visual display of the category label (natural element or phenomenon, result of human activity), pre- sented for 1,000 msec on a computer screen located in front of the participant. The auditory stimulus was presented $600 \mathrm{msec}$ later. The participants were asked to decide as quickly as possible whether the auditory stimulus matched the category label or not by pushing the yes or no key of the PsyScope buttonbox. Trials in the gender categorization task began with a visual warning signal (“*”) for $200 \mathrm{msec}$. It was followed, $400 \mathrm{msec}$ later, by the auditory stimulus. The participants were asked to decide as quickly as possible whether the stimulus word was masculine or feminine. Latencies were measured from the onset of the auditory stimulus to the participant's response. The intertrial interval was $1,500 \mathrm{msec}$. There were 18 practice word trials in the semantic categorization task and 16 trials in the gender categorization task.

\section{RESULTS}

Response latencies exceeding 2,000 msec or three standard deviations above the participant mean were not included in the response time analyses on correct responses (3.6\% and $0.7 \%$ of the data in the semantic and gender categorization tasks, respectively). The mean response latencies and the percentages of correct responses are presented in Table 2. ANOVAs with the consistency factor were conducted separately, with participants $\left(F_{1}\right)$ and items $\left(F_{2}\right)$ as random factors. For both tasks, in the byitem analyses, the consistency effect on latencies was as-

Table 2

Mean Response Latencies (in Milliseconds) and Percentages of Correct Responses in the Semantic Categorization and Gender Categorization Tasks

\begin{tabular}{|c|c|c|c|c|c|c|c|c|c|c|}
\hline & \multicolumn{5}{|c|}{ Semantic Categorization } & \multicolumn{5}{|c|}{ Gender Categorization } \\
\hline & \multicolumn{2}{|c|}{ Consistent } & \multicolumn{2}{|c|}{ Inconsistent } & \multirow[b]{2}{*}{ Effect } & \multicolumn{2}{|c|}{ Consistent } & \multicolumn{2}{|c|}{ Inconsistent } & \multirow[b]{2}{*}{ Effect } \\
\hline & $M$ & $S D$ & $M$ & $S D$ & & $M$ & $S D$ & $M$ & $S D$ & \\
\hline Response latency & 1,128 & 133 & 1,186 & 134 & 58 & 859 & 89 & 913 & 80 & 54 \\
\hline Percent correct & 87.6 & 0.08 & 81.0 & 0.10 & 6.6 & 91.6 & 0.07 & 87.6 & 0.06 & 4.0 \\
\hline
\end{tabular}


sessed after word duration was taken into account (as a covariate). Categorization difficulty was used as an additional covariate in the semantic categorization task. Note that the position of the uniqueness point was not used as a covariate, since most of the stimuli had their uniqueness point after the last phoneme.

\section{Semantic Categorization}

Analyses on latencies indicated a significant 58-msec advantage for consistent words over inconsistent ones $\left[F_{1}(1,41)=18.01, p<.001 ; F_{2}(1,50)=6.76, p<.025\right]$. Both covariates used in the by-item analysis were significant $\left[F_{2}(1,50)=8.56, p<.01\right.$, and $F_{2}(1,50)=25.86, p<$ .001 , for auditory word duration and semantic categorization difficulty, respectively]. Finally, analyses on accuracy percentages also revealed a significant consistency effect $\left[F_{1}(1,41)=18.08, p<.001 ; F_{2}(1,52)=6.67, p<\right.$ $.025]$.

\section{Gender Categorization}

Consistent words had a 54-msec advantage over inconsistent words $\left[F_{1}(1,35)=91.41, p<.001 ; F_{2}(1,53)=\right.$ $5.99, p<.025]$. Auditory word duration, which was used as a covariate in the by-item analysis for latency, was significant $\left[F_{2}(1,53)=35.85, p<.001\right]$. For accuracy, the consistency factor was significant only in the byparticipant analysis $\left[F_{1}(1,35)=10.13, p<.01 ; F_{2}<1\right]$.

\section{DISCUSSION}

The present study assessed whether orthographic consistency would influence semantic and gender categorization performance on auditorily presented words. As was mentioned before, much of the previous effort in examining the impact of orthographic consistency in spoken word recognition had concentrated on the lexical decision task, thus leaving open the possibility that the orthographic effects ensue from specific lexical decision mechanisms. For example, it remains possible that difficulties in quickly identifying short words (Pitt \& Samuel, 2006), which are generally phonologically similar to many other words, led participants to evaluate the orthographic familiarity of the stimuli to assist in making lexicality judgments. In this case, inconsistent words would be disadvantaged because they are generally less familiar, orthographically, than consistent words (e.g., have fewer orthographic neighbors). Although such an account does not hold for the consistency effects that occurred in the semantic and gender categorization tasks, it remains possible that the effects result from the usefulness of orthographic information for assisting decisional processes. Indeed, Onnis and Christiansen (2008) have shown that phonemes occurring at the word edges provide information about grammatical categories (nouns, verbs), and a similar role for the orthographic and phonological properties of the stimuli in semantic categorization cannot be ruled out. Unfortunately, this hypothesis cannot be evaluated with regard to the semantic categorization task, due to the lack of lexical databases providing information about the semantic features of French words. Nevertheless, in the gender categorization task, the exploitation of orthography to assist decision processes should have yielded an advantage of inconsistent over consistent words, because the former were more gender consistent than were the latter in their orthographic properties (see Table 1). Hence, the present data argue in favor of orthographic influences that take place before decisional processes.

In addition to adding to a growing body of evidence suggesting that orthographic knowledge affects spoken word recognition (e.g., Chéreau, Gaskell, \& Dumay, 2007; Taft, Castles, Davis, Lazendic, \& Nguyen-Hoan, 2008; Ventura et al., 2004; Ziegler et al., 2004), the present findings indicate that orthographic influences are not restricted to lexical access but that they expand to semantic and grammatical access. Although differences in the overall level of performance across tasks, as well as in stimulus material, render the comparison hazardous, it is worth noting that the absolute sizes of the effects were similar in the two tasks ( 58 and $54 \mathrm{msec}$ ) and were similar in magnitude to the effects described previously in lexical decision studies (generally, between 50 and $80 \mathrm{msec}$ ). The main point, however, is that despite the fact that semantic/ grammatical knowledge can be hypothesized to be more strongly bound up with phonology than with orthography, due to the primacy of spoken over written language, orthography influences semantic and grammatical access.

According to the adaptive resonance model (Stone \& Van Orden, 1994), word recognition results from ongoing interactions between elementary units - coding for orthographic, phonological, and semantic features - that continue until a stable state of activation is reached. With activation flowing back and forth between orthographic and phonological units during word processing, any inconsistency in the mappings between orthography and phonology should weaken the stability of the feedback loop and, thus, should delay recognition. This model offers a nice framework for accounting for orthographic influences on spoken word recognition, since it assumes fast orthographic activation during processing, but the additional key assumption that activation reverberates between orthographic and phonological units has not yet received clear empirical support. In particular, several studies on printed word recognition have failed to show that consistency in the mapping between phonology and orthography (i.e., feedback consistency) influences performance (Kessler, Treiman, \& Mullennix, 2007; Peereman, Content, \& Bonin, 1998; Ziegler, Petrova, \& Ferrand, 2008). Turning to the models specifically developed for spoken word recognition, none of them allow orthographic knowledge to affect performance. For example, in both TRACE (McClelland \& Elman, 1986) and the neighborhood activation model (Luce, Goldinger, Auer, \& Vitevitch, 2000), word recognition is considered to result from a match between the phonological/articulatory features of the input signal and the lexical representations. In such models, orthographic influences would likely show up if their architectures included sublexical associations between phonological and orthographic codes. Early activation of phonological/articulatory features would propa- 
gate to the corresponding orthographic codes, and lexical access would therefore depend on both phonological and orthographic activation. Because inconsistent words are characterized by inconsistent mappings between phonology and orthography, the contribution of orthography to lexical access should be weaker than that for consistent words, thus resulting in a disadvantage for inconsistent words. On the basis of this outline, the effects observed in the semantic and gender categorization tasks may indicate that access to semantic and grammatical features is constrained by both phonological and orthographic activation within the lexicon. This hypothesis would necessitate, however, positing sufficiently strong connections between orthography and semantic features to bypass the primacy of spoken language from a developmental perspective and in everyday usage.

Alternatively, orthographic influences in spoken word recognition could result from phonological representations' progressively embodying orthographic characteristics during literacy acquisition. Although many studies have shown that literacy has an impact on the ability of segmental analysis of speech (Morais et al., 1979), very little is currently known about the potential influence of learning to read and spell words on the phonological representations of words. However, given the assumption that phonological knowledge is restructured as a function of language experience (e.g., Metsala \& Walley, 1998), the orthographic properties of words may partially shape how phonological representations are organized. According to this view, orthographic effects in spoken word recognition do not follow from the online involvement of orthography during recognition, but from the fact that the orthographic characteristics of words partially constrain how phonological representations are restructured during literacy acquisition. This possibility was examined recently (Peereman, Benbousselham, Dufour, \& Bonin, 2007; Peereman et al., 2008), using a feedforward connectionist network associating phonological input to corresponding phonological output (auto-associator). After a first phase of training on phonology alone, spelling acquisition began by teaching the network to also associate orthographic output with the phonological input. It was found that the internal representations of the network were reorganized during spelling acquisition, so that consistency of the mappings between phonology and orthography started to affect the accuracy of phonological output patterns.

To conclude, although further work is required to determine the foundation of the orthographic influences in spoken word recognition, the present findings extend previous observations in two important ways. First, orthographic consistency does not appear to tap task-specific processes, and second, the orthographic influences in spoken word recognition also emerge in tasks requiring word processing beyond simple lexical access.

\section{AUTHOR NOTE}

This research was presented at the 48th Annual Meeting of the Psychonomic Society, Long Beach, CA, November 2007. This work was supported by a grant from the Conseil Régional de Bourgogne (Contrat de Plan Etat-Région 2006 to R.P.). The authors are grateful to Stephen D. Goldinger and two anonymous reviewers for their insightful comments. Correspondence concerning this article should be addressed to R. Peereman, Laboratoire de Psychologie et Neurocognition, C.N.R.S. U.M.R. 5105, Université Pierre Mendès-France, BP 47,38040 Grenoble Cedex 9 , France (e-mail: ronald.peereman@upmf-grenoble.fr).

\section{REFERENCES}

Booth, J. R., Burman, D. D., Meyer, J. R., Gitelman, D. R., Parrish, T. B., \& Mesulam, M. M. (2004). Development of brain mechanisms for processing orthographic and phonologic representations. Journal of Cognitive Neuroscience, 16, 1234-1249.

Bordag, D., Opitz, A., \& Pechmann, T. (2006). Gender processing in first and second languages: The role of noun termination. Journal of Experimental Psychology: Learning, Memory, \& Cognition, 32, 1090-1101.

Chéreau, C., Gaskell, M. G., \& Dumay, N. (2007). Reading spoken words: Orthographic effects in auditory priming. Cognition, 102, 341360 .

Cheung, H., Chen, H.-C., LaI, C. Y., Wong, O. C., \& Hills, M. (2001). The development of phonological awareness: Effects of spoken language experience and orthography. Cognition, 81, 227-241.

Cohen, J., MacWhinney, B., Flatt, M., Provost, J. (1993). PsyScope: An interactive graphic system for designing and controlling experiments in the psychology laboratory using Macintosh computers. Behavior Research Methods, Instruments, \& Computers, 25, 257-271.

Dijkstra, T., Roelofs, A., \& Fieuws, S. (1995). Orthographic effects on phoneme monitoring. Canadian Journal of Experimental Psychology, 49, 264-271.

Dufour, S., Peereman, R., Pallier, C., \& Radeau, M. (2002). Vocolex: Une base de données lexicales sur les similarités phonologiques entre les mots français. L'Année Psychologique, 102, 725-746.

Grainger, J., \& JACOBS, A. M. (1996). Orthographic processing in visual word recognition: A multiple read-out model. Psychological Review, 103, 518-565.

Hallé, P. A., Chéreau, C., \& Segui, J. (2000). Where is the /b/ in "absurde" [apsyrd]? It is in French listeners' minds. Journal of Memory \& Language, 43, 618-639.

Holmes, V. M., \& Dejean de la Bâtie, B. (1999). Assignment of grammatical gender by native speakers and foreign learners of French. Applied Psycholinguistics, 20, 479-506.

Kessler, B., Treiman, R., \& Mullennix, J. (2007). Feedbackconsistency effects in single-word reading. In E. L. Grigorenko \& A. J. Naples (Eds.), Single-word reading: Behavioral and biological perspectives (pp. 159-174). Mahwah, NJ: Erlbaum.

LIBERMAN, A. (1992). The relation of speech to reading and writing. In R. Frost \& L. Katz (Eds.), Orthography, phonology, morphology, and meaning (pp. 167-178). Amsterdam: Elsevier, North-Holland.

Luce, P. A., Goldinger, S. D., Auer, E. T., Jr., \& Vitevitch, M. S. (2000). Phonetic priming, neighborhood activation, and PARSYN. Perception \& Psychophysics, 62, 615-625.

McClelland, J. L., \& Elman, J. L. (1986). The TRACE model of speech perception. Cognitive Psychology, 18, 1-86.

Metsala, J. L., \& Walley, A. C. (1998). Spoken vocabulary growth and the segmental restructuring of lexical representations: Precursors to phonemic awareness and early reading abilities. In J. L. Metsala \& L. C. Ehri (Eds.), Word recognition in beginning literacy (pp. 89-120). Mahwah, NJ: Erlbaum.

Morais, J., Cary, L., Alegria, J., \& Bertelson, P. (1979). Does awareness of speech as a sequence of phones arise spontaneously? Cognition, 7, 323-331.

New, B., Pallier, C., Brysbaert, M., \& Ferrand, L. (2004). Lexique 2: A new French lexical database. Behavior Research Methods, Instruments, \& Computers, 36, 516-524.

Onnis, L., \& Christiansen, M. H. (2008). Lexical categories at the edge of the word. Cognitive Science, 32, 184-221.

Pattamadilok, C., Morais, J., Ventura, P., \& Kolinsky, R. (2007). The locus of the orthographic consistency effect in auditory word recognition: Further evidence from French. Language \& Cognitive Processes, 22, 700-726.

Peereman, R., Benbousselham, I., Dufour, S., \& Bonin, P. (2007, 
November). Does orthography matter in auditory word recognition? Converging evidence from different tasks. Paper presented at the 48th Annual Meeting of the Psychonomic Society, Long Beach, CA.

Peereman, R., Bonin, P., \& Dufour, S. (2008). Orthography in spokenword recognition: The consistency effect. Manuscript submitted for publication.

Peereman, R., \& Content, A. (1999). LeXOP: A lexical database providing orthography-phonology statistics for French monosyllabic words. Behavior Research Methods, Instruments, \& Computers, 31, 376-379.

Peereman, R., Content, A., \& Bonin, P. (1998). Is perception a twoway street? The case of feedback consistency in visual word recognition. Journal of Memory \& Language, 39, 151-174.

Perre, L., \& Ziegler, J. C. (2008). On-line activation of orthography in spoken word recognition. Brain Research, 1188, 132-138.

PitT, M. A., \& SAmuel, A. G. (2006). Word length and lexical activation: Longer is better. Journal of Experimental Psychology: Human Perception \& Performance, 32, 1120-1135.

Seidenberg, M. S., \& Tanenhaus, M. K. (1979). Orthographic effects on rhyme monitoring. Journal of Experimental Psychology: Human Learning \& Memory, 5, 546-554.

Stone, G. O., \& VAN ORden, G. C. (1994). Building a resonance framework for word recognition using design and systems principles. Journal of Experimental Psychology: Human Perception \& Performance, 20, 1248-1268.
Taft, M., Castles, A., Davis, C., Lazendic, G., \& Nguyen-Hoan, M. (2008). Automatic activation of orthography in spoken word recognition: Pseudohomograph priming. Journal of Memory \& Language, $\mathbf{5 8}, 366-379$.

Van Orden, G. C., Pennington, B. F., \& Stone, G. O. (1990). Word identification in reading and the promise of subsymbolic psycholinguistics. Psychological Review, 97, 488-522.

Ventura, P., Morais, J., Pattamadilok, C., \& Kolinsky, R. (2004). The locus of the orthographic consistency effect in auditory word recognition. Language \& Cognitive Processes, 19, 57-95.

Ziegler, J. C., \& FerRand, L. (1998). Orthography shapes the perception of speech: The consistency effect in auditory word recognition. Psychonomic Bulletin \& Review, 5, 683-689.

Ziegler, J. C., Ferrand, L., \& Montant, M. (2004). Visual phonology: The effects of orthographic consistency on different auditory word recognition tasks. Memory \& Cognition, 32, 732-741.

Ziegler, J. C., Petrova, A., \& Ferrand, L. (2008). Feedback consistency effects in visual and auditory word recognition: Where do we stand after more than a decade? Journal of Experimental Psychology: Learning, Memory, \& Cognition, 34, 643-661.

(Manuscript received March 17, 2008; revision accepted for publication September 12, 2008.) 